Int. J. Curr. Res. Med. Sci. (2018). 4(5): 59-61

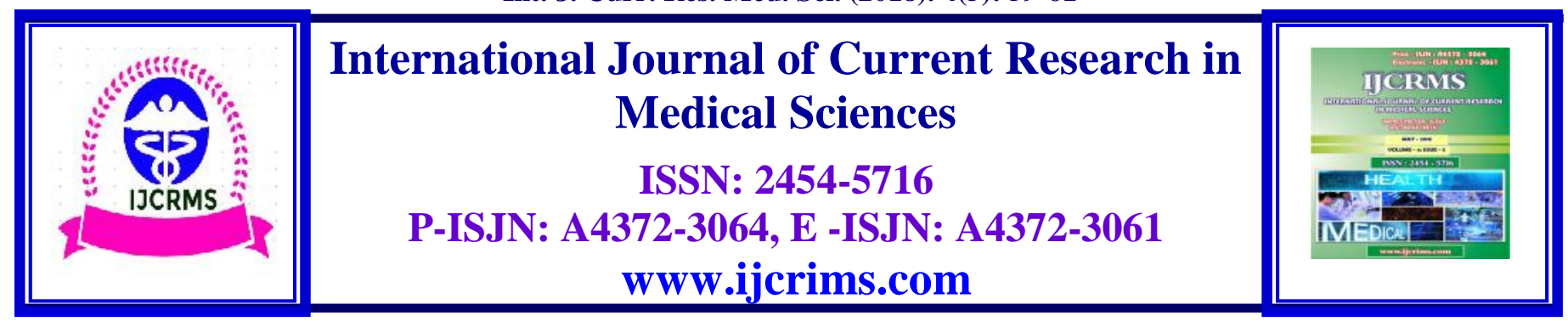

Case Report

Volume 4, Issue 5 -2018

DOI: http://dx.doi.org/10.22192/ijcrms.2018.04.05.009

\title{
Cholecystoduodenal fistula with small contracted gall bladder: A case report with review of literature
}

\author{
Satpal Hans", Devika Krishnakumar"*, Anand Dutta ${ }^{* *}$, Sahil Mashal ${ }^{* *}$, \\ Parneet ${ }^{* *}$, N.S.Neki***, Prikshit Bhargav" \\ *Professor ,**Junior Resident, Department of General Surgery, \\ Govt. Medical College/Guru Nanak Dev Hospital, Amritsar, India. \\ ***Professor \& Head, Dept. of Medicine, \\ Govt. Medical College/Guru Nanak Dev Hospital, Amritsar, India \\ ****MBBS Final Year student, Govt. Medical College, Amritsar, India \\ Corresponding author: Dr. Devika Krishnakumar \\ Junior Resident, Department of Surgery, Room no. 40, NRI Girls Hostel \\ GMC\& GNDH Amritsar, Punjab \\ E-mail:drananddutta@gmail.com
}

\section{Abstract}

Internal billiary fistulas like cholecystoduodenal fistula is an uncommon complication of cholelithiasis occurring in about $0.15 \%$ to $5 \%$ of the cases. Herein we report a case of cholecystoduodenal fistula in a 55 year old female patient and update its surgical management.

Keywords: Cholecystoduodenal Fistula, Biliary Fistulas

\section{Introduction}

A biliary fistula is an abnormal passage or communication from the biliary system to an organ or cavity or free surfaces. Biliary fistulas are classified as external biliary fistulas(biliary cutaneous fistula) or internal biliary fistula (biliobiliary, bilioenteric, bronchobiliary). Internal biliary fistulas is associated with chronic cholelithiasis in $90 \%$ of the cases ${ }^{1}$. Cholecystodudenal fistula is the commonest form of bilioenteric fistula ${ }^{2}$.

\section{Case Report}

A 55 year old female patient reported with right upper quadrant pain for last three months. The pain was intermittent in nature relieved by medications and not associated with vomiting jaundice or fever. She had exacerbation of her symptoms for past 1 week. Her MRCP report showed small contracted gall bladder with cholecystoduodenal fistula in $1^{\text {st }}$ part of duodenum due to cholelithiasis (shown in figure 1,2). 
All her routine blood investigations was within normal limits. She was admitted and initially managed with intravenous antibiotics analgesics and then taken up for elective surgery. Intra operatively the gall bladder was found to be small and contracted with no calculi within the gall bladder. A fistulous connection was found in relation to the $1^{\text {st }}$ part of duodenum. Cholecystectomy was done followed by resection

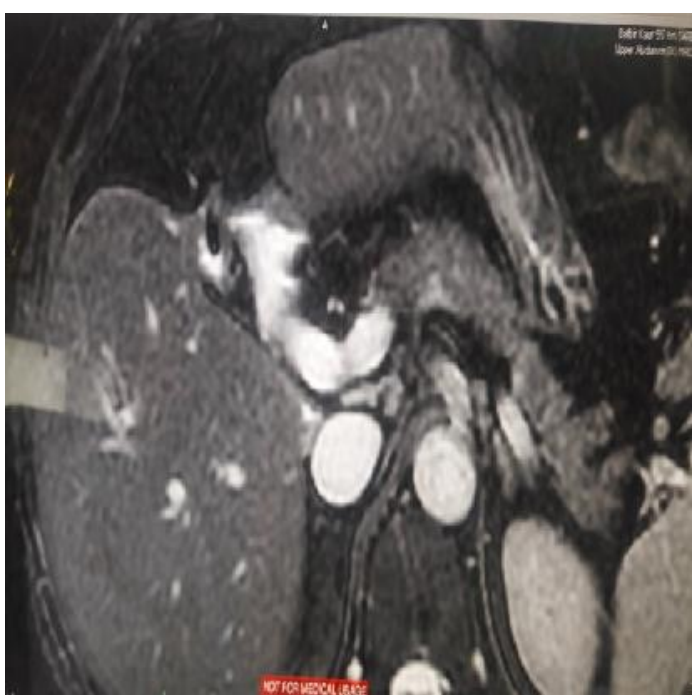

Figure : 1 (MRCP report showing cholecystoduodenal fistula )

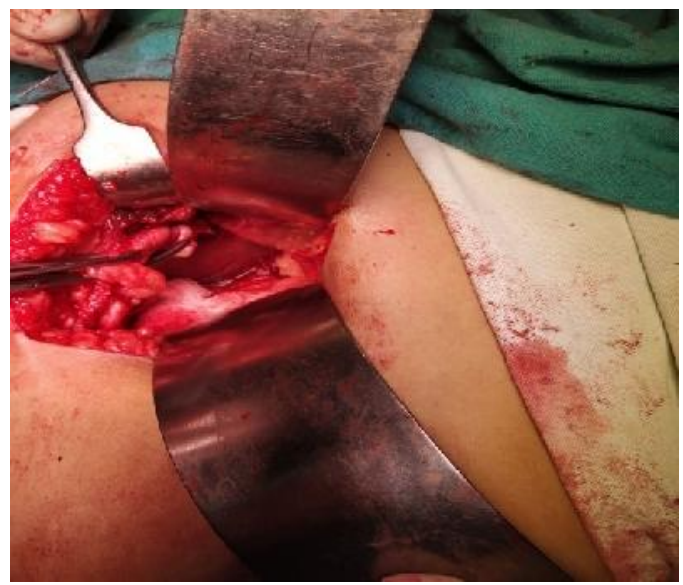

Figure : 3 ( intraoperative picture showing cholecystoduodenal fistula )

\section{Discussion}

Internal biliary fistulas occur due to acute inflammation with obstruction of cystic duct resulting in adhesion of gall bladder to adjacent viscera usually to duodenum and repeated attacks of inflammation resulting in gangrenous changes of fistula and closure of defect in duodenum. Common bile duct was explored showed no calculi. The patient was kept nil orally and under ryles tube aspiration for two days post operatively. Liquids were allowed on third post operative day followed by semisolids. Patient was discharged within one week. Patient was completely symptom free at the time of discharge.

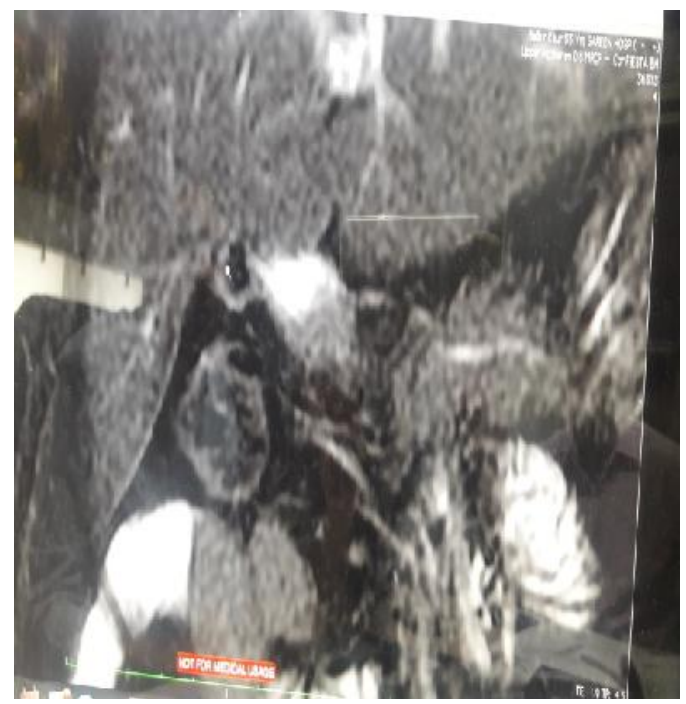

Figure : 2 (MRCP report showing abnormal communication between gall bladder and $1 \mathrm{st}$ part of duodenum)

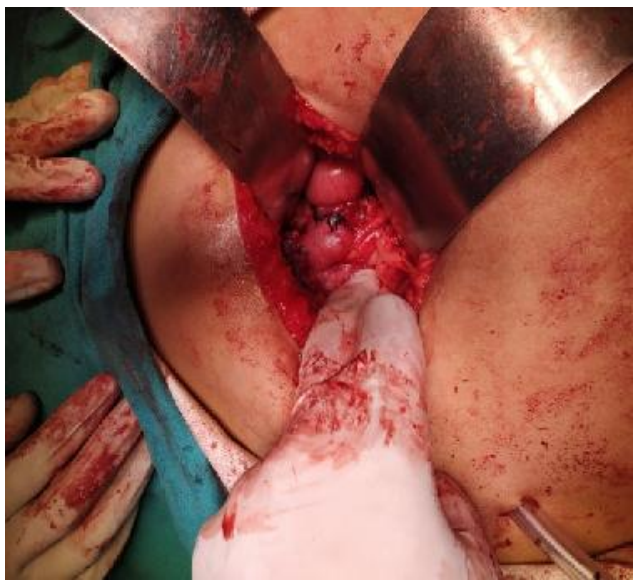

Figure : 4 ( Intraoperative picture showing repair of cholecystoduodenal fistula)

of gall bladder wall and the wall of adherent viscus with eventual erosion and fistula formation 3. The common causes of internal biliary fistula formation includes cholelithiasis, peptic ulceration, malignant neoplasms (gall bladder, bile duct, duodenum, pancreas) Crohn's disease of duodenum and paraduodenal abscess ${ }^{4,5}$. 
Symptoms of internal biliary fistulas includeabdominal pain, fever, nausea, vomiting, flatulence, diarrhoea, weight loss all of which are non specific and seen in gastro intestinal pathologies ${ }^{6}$. The diagnosis is often non specific pre operatively. Most internal biliary fistulas are detected by MRCP or $\mathrm{ERCP}^{7}$. Cholecystoduodenal fistula is the most common type (70-90\%) followed by cholecysto colonic (10\%), choledochoduodenal, choledochogastric, cholecystogastric and duodeno left hepatic duct fistula ${ }^{8}$. The surgery of choice for management of cholecystoduodenal fistula is cholecystectomy resection of fistula closure of defect in duodenum and exploration of common bile duct. Most of the cases of fistula is associated with common bile duct stones. Another choice of surgery is cholecystectomy followed by choledochoduodenostomy through the fistula ${ }^{9}$. Initially laparoscopic management of cholecystoduodenal fistula was contra indicated. But nowadays laparoscopic management of internal biliary fistula is also done with success ${ }^{10}$.

\section{Conflicts of interest: None}

Financial support: None

\section{References}

1. Safaie-Shirazi S, Zike WL, Printen KJ. Spontaneous enterobiliary fistulas. Surg Gynecol Obstet.1973;137:769-772.
2. Sapuła R, Skibiński W. Gallstone ileus as a complication of cholecystolithiasis. Surg Endosc. 2002;16:360.

3. LeBlanc KA, Barr LH, Rush BM. Spontaneous biliary enteric fistulas. South Med J. 1983;76:1249-1252.

4. Schumacher G, Keck H, Neuhaus P. Cholecystoduodenal fistula with subsequent gallstone ileus: case report of an unusual course. Zentralbl Chir. 1996;121:408-411.

5. Jones TA, Davis ME, Glantz AI. Bouveret's syndrome presenting as upper gastrointestinal hemorrhage without hematemesis. Am Surg. 2001;67:786-789.

6. Topal U, Savci G, Sadikoglu MY, Tuncel E. Choledochoduodenal fistula secondary to duodenal peptic ulcer. A case report. Acta Radiol. 1997;38:1007-1009.

7. Atli AO, Coşkun T, Ozenç A, Hersek E. Biliary enteric fistulas. Int Surg. 1997;82:280-283.

8. Giani L, Nobili P, Corti GL, Cacopardo E. Gallstone ileus. Our experience. G Chir. 1995;16:227-232.

9. Dutta U, Nagi B, Kumar A, Vaiphei K, Wig JD, Singh K. Pneumobilia--clue to an unusual cause of diarrhea.Trop Gastroenterol. 2002;23:138-140.

10. Goldberg RI, Phillips RS, Barkin JS. Spontaneous cholecystocolonic fistula treated by endoscopic sphincterotomy. Gastrointest Endosc. 1988;34:55-56.

\begin{tabular}{|c|l|}
\hline \multicolumn{2}{|c|}{ Access this Article in Online } \\
\hline Quick Response Code & Website: \\
& Www.ijcrims.com \\
\hline Subject: \\
\hline
\end{tabular}

How to cite this article:

Satpal Hans, Devika Krishnakumar, Anand Dutta, Sahil Mashal, Parneet, N.S.Neki, Prikshit Bhargav. (2018). Cholecystoduodenal fistula with small contracted gall bladder: A case report with review of literature. Int. J. Curr. Res. Med. Sci. 4(5): 59-61.

DOI: http://dx.doi.org/10.22192/ijcrms.2018.04.05.009 